\title{
Numerical Analysis on Flexural Behaviors of Prestressed Reinforced Concrete Beams Strengthened with NSM CFRP Strips
}

\author{
Jia Yang $(\mathbb{D}$, Xiao Liu $\mathbb{D}$, and Wei Li \\ College of Architectural Engineering, Shenyang University, Shenyang 110044, China \\ Correspondence should be addressed to Jia Yang; sydxyj@163.com and Xiao Liu; 112656782@qq.com
}

Received 30 July 2021; Revised 2 October 2021; Accepted 2 November 2021; Published 19 November 2021

Academic Editor: Ivan Giorgio

Copyright (c) 2021 Jia Yang et al. This is an open access article distributed under the Creative Commons Attribution License, which permits unrestricted use, distribution, and reproduction in any medium, provided the original work is properly cited.

\begin{abstract}
This paper presents the numerical analysis of prestressed reinforced concrete (PRC) beams strengthened with near-surface mounted (NSM) carbon fiber reinforced polymers (CFRP). ABAQUS finite element software was used to simulate the existing test beams to investigate the flexural behaviors of PRC beams strengthened with NSM CFRP strips. The finite element model of beams strengthened with NSM CFRP strips was established. The finite element calculation results were compared with the experimental results to verify the accuracy and effectiveness of the model. Based on this model, the influences of concrete strength grade and amount of CFRP strips on the flexural behaviors of directly strengthened beams and the cycle numbers and overload amplitude on the flexural behaviors of damaged strengthened beam were further analyzed, and the load-carrying capacity calculation formula of PRC beam strengthened with NSM CFRP strips was established. The results showed that the simulation results and the theoretical calculation were consistent with the test results. With the increase of concrete strength grade and amount of CFRP strips, the ultimate load of directly strengthened beams increased significantly, with a maximum increase of $21.3 \%$ and $23.0 \%$, respectively. When the concrete strength grade exceeded C50, the improvement of the ultimate load was limited. When the overload amplitude was less than $60 \%$ of the ultimate load, the cycle numbers (within 500 times) had little effect on the yield load, ultimate load, and deformation. When the overload amplitude was higher than $60 \%$ of the ultimate load, the deformation increased, and the ultimate load decreased with the increase of the cycle numbers. The larger the overload amplitude, the smaller the ultimate load, and the larger the deformation under the same cycle numbers.
\end{abstract}

\section{Introduction}

CFRP are widely used in structural reinforcement projects because of its lightweight, high strength, and corrosion resistance. The most common CFRP strengthening method of reinforced concrete beams is to externally bond (EB) CFRP laminates onto the soffit of the beam [1]. However, the effectiveness of this system is limited by the most common debonding failure mode, which occurs at an effective strain much lower than the ultimate strain achievable by the CFRP composite materials [2]. NSM CFRP technique involves cutting grooves in the concrete cover, filling the grooves with adhesive, and embedding CFRP bars or strips into the grooves $[3,4]$. The new method of structural reinforcement has the remarkable advantages of good antistripping performance, the high utilization rate of CFRP, and convenient construction. Therefore, it has been widely used in the field of engineering structural reinforcement and reconstruction in recent years.

A lot of researches had been carried out on concrete beams strengthened with NSM CFRP [5-11]. Teng et al. [12] carried out reinforcement test research by using the NSM CFRP strip strengthening technique. In the test, the failure mode and strain distribution of CFRP strips were analyzed. The results showed that the ultimate load and stiffness after cracking of the beams strengthened with NSM CFRP were greatly improved. El-Gamal et al. [13] conducted experimental research on beams strengthened with NSM CFRP and GFRP bars. The research parameters were type, amount, and reinforcement ratio of FRP. The test results showed that the load-carrying capacity of the strengthened beam was $31 \% \sim 133 \%$ higher than that of the control beam. Dias et al. 
[14] conducted an experimental study on the flexural strengthening performance of reinforced concrete beams by using the strengthening technique of NSM CFRP strips and tested one unstrengthened control beam and three strengthened beams with different amounts of CFRP. The test results showed that the NSM CFRP strips were very effective for the flexural reinforcement of reinforced concrete beams, which could effectively improve the cracking, yield, and ultimate load of beams. A large number of theoretical and experimental studies have been carried out on the flexural behavior of concrete beams strengthened with NSM CFRP strips, and some research results have been obtained. However, there are relatively few studies on PRC beams strengthened with NSM CFRP strips. In addition, most of the beams that need to be strengthened in engineering practice are damaged beams under repeated load. Because the parameters of test analysis are limited, the loadcarrying capacity of strengthened beams under specific loading times cannot be analyzed comprehensively. Therefore, in this paper, the flexural behaviors of PRC beams strengthened with NSM CFRP strips are studied using ABAQUS finite element. The model of strengthened beams is established. The correctness of the numerical model is verified by comparing it with the experimental results. Using the verified model, the influences of concrete strength grade, amount of CFRP strips, cycle numbers, and overload amplitude on the flexural behaviors of strengthened beams are further analyzed. The calculation formula of load carrying capacity is given and verified by the test and simulated data. This modeling method has applicability in simulating the mechanical properties of PRC beams strengthened with NSM CFRP strips and can be applied to the subsequent mechanical properties analysis.

\section{Experimental Program}

The simulated test beams in this paper come from reference [15]. All of the test beams were unbonded PRC T-beams with a length of $4.5 \mathrm{~m}$ and a net span of $4.3 \mathrm{~m}$. The design strength grade of the concrete was C40. The longitudinal reinforcements in the concrete web and flange were $16 \mathrm{~mm}$ HRB-335 and $10 \mathrm{~mm}$ HPB-300, respectively. The stirrups in the concrete flange were $6 \mathrm{~mm}$ diameter with a spacing of $200 \mathrm{~mm}$ and, in the concrete web, were $8 \mathrm{~mm}$ diameter with a spacing of $100 \mathrm{~mm}$ and $120 \mathrm{~mm}$ at the end and midspan, respectively. Two 1,860 high strength and low relaxation steel strands were used for prestressed reinforcement. The section dimension and reinforcement of the test beam are shown in Figure 1.

The design parameters and results of the test beams are presented in Table 1.

The specific test steps are as follows:

(1) The yield load $P_{y}$ and ultimate load $P_{u 0}$ of unstrengthened control beam PCB0 are tested.

(2) To simulate overload damages, the initial damages are performed on the beams MPCB1 MPCB4 by cycle loading through different cycle numbers and overload amplitudes before strengthening. As

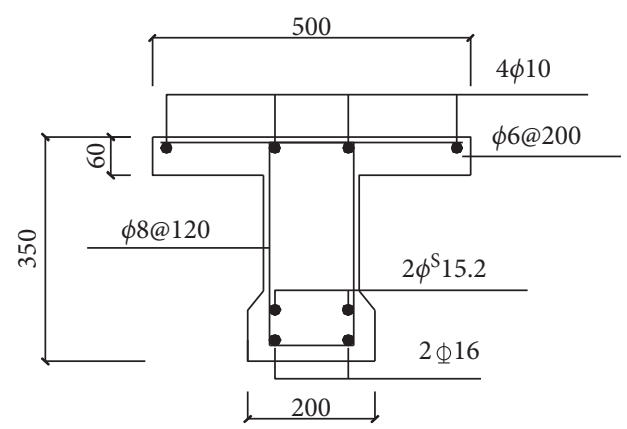

Figure 1: Section dimension and reinforcement of test beams (unit: $\mathrm{mm}$ ).

stipulated by the American Association of State Highway and Transportation Officials [16], the internal reinforcement stress of bridge members in serviceability limit state shall not exceed $60 \%$ of the yield stress of the reinforcement, and any value that exceeds this limit shall be considered an overload. Hence, in this study, 0.9 and 1.3 times yield load of the control beam are considered upper limits of overload amplitude, and 0.1 times yield load is the lower limit. The cycle numbers are taken as 1,50 , and 100 times, respectively.

(3) After the initial damage, these beams are strengthened with NSM CFRP strips under different sustained loads. They are inversely erected on the loading device and reloaded to different sustained loads $0.9 P_{y}$ or $1.3 P_{y}$ (MPCB1-MPCB3: $105 \mathrm{kN}$ and MPCB4: $150 \mathrm{kN}$ ). CFRP plates were cut into strips with dimensions of $3,000 \mathrm{~mm} \times 10 \mathrm{~mm} \times 1.2 \mathrm{~mm}$. Three CFRP strips were bonded together to form a whole and embedded into the two grooves, respectively, after the adhesive was solidified for $24 \mathrm{~h}$. The strengthening process is shown in Figure 2.

(4) Then the load test is continued until the failure after the curing period. The ultimate load of each strengthened beam is obtained.

\section{Establishment and Verification of Finite Element Model}

\subsection{Establishment of Finite Element Model}

3.1.1. Unit Selection. The numerical analysis was performed using the software ABAQUS. Three-dimensional element (C3D8R) was used for concrete; three-dimensional truss element (T3D2) was used for ordinary reinforcement and prestressed reinforcement; and C3D8R solid element was used for CFRP strips.

\subsubsection{Material Properties and Parameter Definition}

(1) Concrete. The plastic damage model of concrete is adopted, which can consider the difference of tensile and compressive strength of concrete, as well as the stiffness degradation and recovery under cycle loading. Therefore, the 
TABLE 1: Design parameters and results of test beams.

\begin{tabular}{|c|c|c|c|c|c|c|}
\hline Specimens & $\begin{array}{l}\text { Upper limits of overload amplitude } \\
\qquad(\mathrm{kN})\end{array}$ & $\begin{array}{l}\text { Cycle number } \\
\text { (times) }\end{array}$ & $\begin{array}{l}\text { Sustained load } \\
(\mathrm{kN})\end{array}$ & Strengthening & ${ }_{P}^{u}(\mathrm{kN})$ & $\begin{array}{l}\text { Failure } \\
\text { modes }\end{array}$ \\
\hline PCB0 & - & - & - & Unstrengthened & 229.4 & A \\
\hline MPCB1 & $0.9 P_{y}$ & 1 & $0.9 P_{y}$ & & 245.8 & $\mathrm{~A}$ and $\mathrm{B}$ \\
\hline MPCB2 & $0.9 P_{y}$ & 50 & $0.9 P_{y}$ & & 260.7 & $\mathrm{~B}$ \\
\hline MPCB3 & $0.9 P_{y}^{y}$ & 100 & $0.9 P_{y}^{y}$ & CFRP strips & 257.6 & B \\
\hline MPCB4 & $1.3 P_{y}$ & 50 & $1.3 P_{y}^{\prime}$ & & 254.6 & $\mathrm{~A}$ and $\mathrm{B}$ \\
\hline
\end{tabular}

Note. $P_{y}$ is measured yield load value of control beam PCB0 and ${ }_{P}^{u}$ is the ultimate load of each specimen. $A=$ concrete crushing in the compressive zone and $B=$ wedge-shaped failure of concrete cover in the tensile zone.

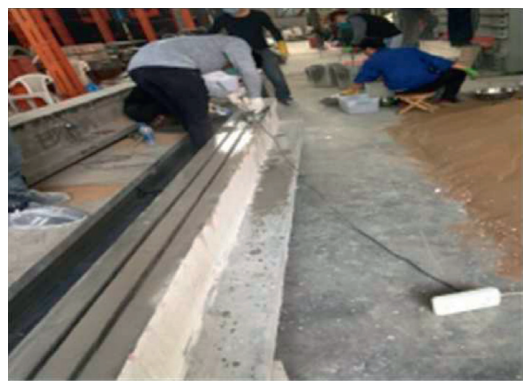

(a)

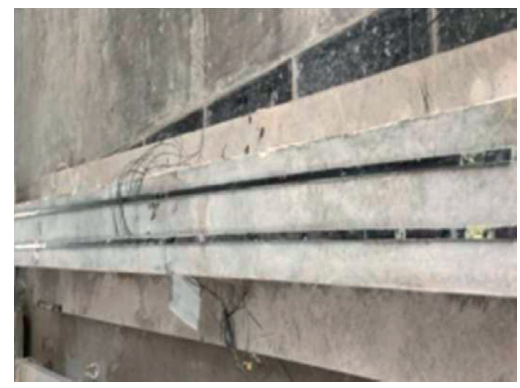

(b)

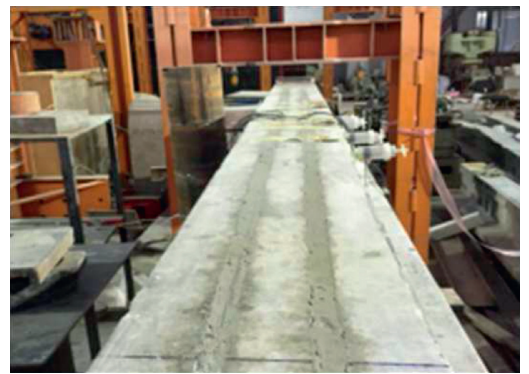

(c)

FIGURE 3: Reinforcement process of specimens: (a) grooving, (b) strip cutting, and (c) strips embedment.

material model can be used to simulate the stiffness degradation of concrete approximately $[17,18]$.

The curve equation is as follows:

$$
\begin{aligned}
& x \leq 1, y=\alpha_{a} x+\left(3-2 \alpha_{a}\right) x^{2}+\left(\alpha_{a}-2\right) x^{3}, \\
& x>1, y=\frac{x}{\alpha_{d}(x-1)^{2}+x},
\end{aligned}
$$

where $y=\sigma / f_{c}, \quad x=\varepsilon / \varepsilon_{c}, \quad \varepsilon_{c}=\left(700+172 \sqrt{f_{c}}\right) \times 10^{-6}$, $\alpha_{a}=2.4-0.0125 f_{c}, \quad \varepsilon_{c u}=\varepsilon_{c}\left(1+2 \alpha_{d}+\sqrt{1+4 \alpha_{d}}\right) / 2 \alpha_{d}$, $\alpha_{d}=0.157 f_{c}^{0.785}-0.905, f_{c}, \varepsilon_{c}$, and $\varepsilon_{c u}$ are uniaxial compressive strength, peak compressive strain, and ultimate compressive strain of concrete respectively.

The stress fracture energy relationship is used to describe the tensile and softening properties of concrete.

(2) Non-Prestressed Steel Reinforcement. The mathematical expression of the stress-strain relationship is as follows [19]:

$$
\sigma= \begin{cases}E_{s} \varepsilon, & \left(\varepsilon \leq \varepsilon_{e}\right), \\ -A \varepsilon^{2}+B_{\varepsilon}+C, & \left(\varepsilon_{e}<\varepsilon \leq \varepsilon_{e 1}\right), \\ f_{y}, & \left(\varepsilon_{e 1}<\varepsilon \leq \varepsilon_{e 2}\right), \\ f_{y}\left[1+0.6 \frac{\varepsilon-\varepsilon_{e 2}}{\varepsilon_{e 3}-\varepsilon_{e 2}}\right], & \left(\varepsilon_{e 2}<\varepsilon \leq \varepsilon_{e 3}\right), \\ 1.6 f_{y}, & \left(\varepsilon>\varepsilon_{t e 3}\right),\end{cases}
$$

where $\quad A=0.2 f_{y} /\left(\varepsilon_{e 1}-\varepsilon\right)^{2}, \quad B=2 A \varepsilon_{e 1}$, $C=0.8 f_{y}+A \varepsilon_{e}^{2}-B \varepsilon_{e}, \quad \varepsilon_{e}=0.8 f_{y} / E_{s}, \quad \varepsilon_{e 1}=1.5 \varepsilon_{e}$, $\varepsilon_{e 2}=10 \varepsilon_{e}, \varepsilon_{e 3}=100 \varepsilon_{e}, E_{s}$ is the elastic modulus of steel reinforcement, and $f_{u}$ is the ultimate strength of steel reinforcement.

(3) Prestressed Steel Reinforcement. The stress-strain relationship is as follows:

$$
\sigma_{p}= \begin{cases}E_{p} \varepsilon_{p}, & \left(\varepsilon_{p} \leq \varepsilon_{p c}\right) \\ f_{p c}+\frac{f_{0.2}-f_{p c}}{\varepsilon_{0.2}-\varepsilon_{p c}}\left(\varepsilon_{p}-\varepsilon_{p c}\right), & \left(\varepsilon_{p c}<\varepsilon_{p} \leq \varepsilon_{0.2}\right) \\ f_{0.2}+\frac{f_{p u}-f_{0.2}}{\varepsilon_{p u}-\varepsilon_{0.2}}\left(\varepsilon_{p}-\varepsilon_{0.2}\right), & \left(\varepsilon_{0.2}<\varepsilon_{p} \leq \varepsilon_{p u}\right)\end{cases}
$$

where $E_{p}$ is the elastic modulus of prestressed steel reinforcements, $\varepsilon_{p u}$ is an ultimate tensile strain of prestressed steel reinforcements, $f_{0.2}$ is the conditional yield strength of prestressed steel reinforcements, $\varepsilon_{0.2}$ is conditional yield strain of prestressed steel reinforcements, $f_{p}$ is elastic limit stress of prestressed steel reinforcements, and $\varepsilon_{p}$ is the ultimate elastic strain of prestressed steel reinforcements.

(4) CFRP Strips. The stress-strain relationship is taken as ideal elasticity [20]. If the fiber stress exceeds its tensile strength, it is considered that the fiber is broken. The stressstrain relationship of CFRP strips is as follows: 


$$
\sigma_{f}= \begin{cases}E_{f} \varepsilon_{f}, & \left(0 \leq \varepsilon_{f} \leq \varepsilon_{f u}\right), \\ 0, & \left(\varepsilon_{f u} \leq \varepsilon_{f}\right),\end{cases}
$$

where $\sigma_{f}$ is the stress of CFRP strips, $E_{f}$ is the elastic modulus of CFRP strips, $\varepsilon_{f}$ is a strain of CFRP strips, and $\varepsilon_{f u}$ is an allowable tensile strain of CFRP strips.

\subsubsection{Prestress Simulation Method. When ABAQUS is used} to simulate prestressed concrete structures, the simulation methods for prestressing steel reinforcement generally include multipoint constraint method (MPC Method), cooling method, equivalent load method, own initial stress method of ABAQUS, rebar element single method, rebar layer method, and so on [21]. In this paper, the cooling method is used, that is, to apply temperature load (cooling) on the prestressed reinforcements, that is, the temperature load is applied to the prestressed steel reinforcements, and the prestressed steel reinforcements are contracted so that the concrete beams are prestressed:

$$
\Delta T=\frac{P}{\alpha E_{p} A_{p}},
$$

where $\alpha$ is the coefficient of linear expansion of prestressed reinforcement, taken as $1.2 \times 10^{-5} /{ }^{\circ} \mathrm{C}$; $\mathrm{T}$ is temperature load; and $P$ is the load value corresponding to temperature decrease.

3.1.4. Load Application. The cycle load is carried out by applying concentrated force according to cycle numbers and overload amplitude. The specimens are subjected to cycle loading, and then the CFRP strips are strengthened. So the CFRP strips do not participate in the stress before reinforcement but after reinforcement. In order to effectively simulate its stress process, the birth and death element technology $[21,22]$ is used for simulation.

3.2. Verification of Finite Element Model. Due to the limited space, this paper only gives the numerical analysis results and model verification of the unstrengthened control beam PCB0 and strengthened beam MPCB4 under loading.

3.2.1. Load and Deformation Analysis. The load-deformation curves of the finite element results were compared with the test results, as shown in Figure 3.

Figure 3(a) shows the comparison of the load-deformation curves of the unstrengthened beam. It can be seen that the simulated load-deformation curve was divided into three stages: the initial elastic stage, the elastic-plastic stage, and the plastic stage. Before cracking, that was, at the initial stage of loading, the simulation curve and the test curve coincide basically. The curve presented a linear distribution. The beam was in the elastic stage. When the calculated load reached $55.6 \mathrm{kN}$ (the test value was $59.6 \mathrm{kN}$ ), the load-deformation curve turned. When the load reached $118 \mathrm{kN}$ (the test value was $116 \mathrm{kN}$ ), the stiffness of the curve decreased, and there was an obvious turning point, which indicated that the reinforcement yielded, and midspan deformation was $14.6 \mathrm{~mm}$ (the test value was $13.7 \mathrm{~mm}$ ). When the calculated load reached $226 \mathrm{kN}$ (the test value was $229.4 \mathrm{kN}$ ), the loaddeformation curve reached the peak, and the maximum deformation of the beam was $119 \mathrm{~mm}$ (the test value was $115 \mathrm{~mm}$ ). Thus, it can be seen that the simulation curve of the control beam was in high agreement with the test result curve, showing an obvious three-stage form. The characteristic points were basically consistent. The simulation results were basically consistent with the test results and tended to be safe.

Figure 3(b) shows the comparison of the load-deformation curves of the strengthened beam MPCB4 between the finite element model results and the test results. For the damaged strengthened beam, the stiffness increased, and the slope of the load-deformation curve increased, and the deformation growth slowed down due to the strengthening effect of CFRP strips. When the load continued to $156.8 \mathrm{kN}$ $(165 \mathrm{kN}$ in the test), the load-deformation curve turned when the midspan deformation was $39.0 \mathrm{~mm}(39.8 \mathrm{~mm}$ in the test), and the stiffness decreased compared with the previous stage. When the load reached $241.0 \mathrm{kN}(254.6 \mathrm{kN}$ in the test), the maximum deformation of the beam was $102.8 \mathrm{~mm}$ ( $95 \mathrm{~mm}$ in the test). It can be seen that the finite element simulation curve of the damaged strengthened beam under loading was similar to the curve of the test result, which was in the form of two stages. The yield and ultimate load were slightly lower than the test value, and the deformation was slightly larger than the test value and is partial to safety.

According to the peak points of each stage of the curve, the load-deformation curve of the typical damaged strengthened beam under loading was obtained, as shown in Figure 4.

According to the yield point and peak load, three key points were selected, and the curve was divided into two stages. The three key points were as follows: point $\mathrm{A}$ was the critical point after strengthened with CFRP under loading; point $\mathrm{B}$ was the yield point of steel reinforcement; and point $\mathrm{C}$ was the load peak point, which was the limit state. The two stages were the elastic-plastic stage ( $\mathrm{AB}$ section) and the plastic stage (BC section). In the elastic-plastic stage, the concrete beam remained elastic-plastic, and the steel reinforcement at point B just yielded. In the plastic stage, from point $B$, the stiffness began to decrease obviously; after that, the load increased slowly, and the deformation increased rapidly until the ultimate load point $\mathrm{C}$.

3.2.2. Stress Analysis. Combined with Figure 4, the stress distribution of concrete beam, steel reinforcements, and CFRP strips along the beam length corresponding to the above three characteristic points (points A, B, and C) was analyzed. The nephogram of stress distribution of concrete beam, steel reinforcements, and CFRP strips along the span direction at the characteristic point is shown in Figure 5.

As shown in Figure 5(a), after cycle loading, CFRP strips were embedded for strengthening under loading. At this 


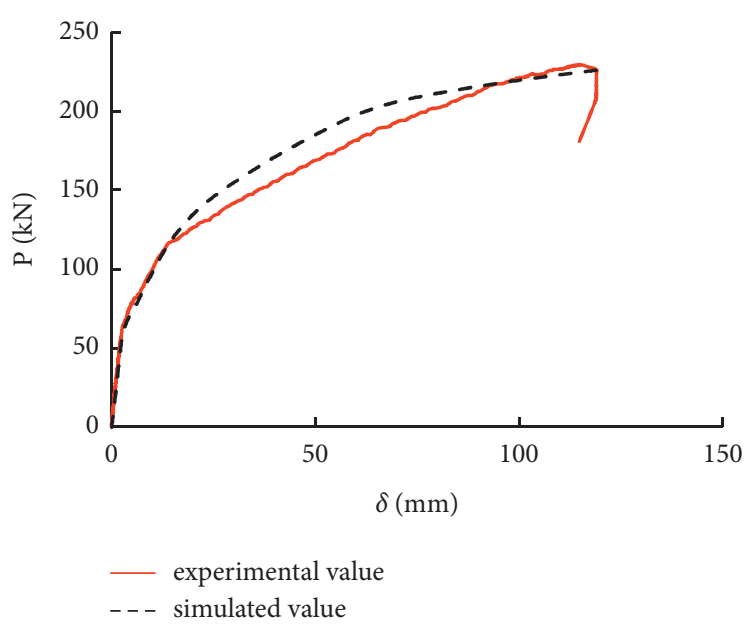

(a)

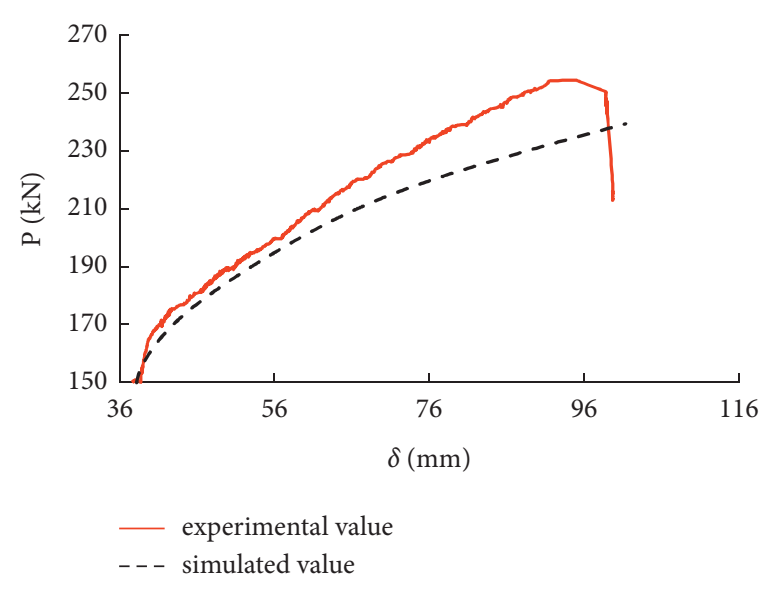

(b)

FIGURE 3: Comparison of the load-deformation curves between simulative and experimental results: (a) PCB0 and (b) MPCB4.

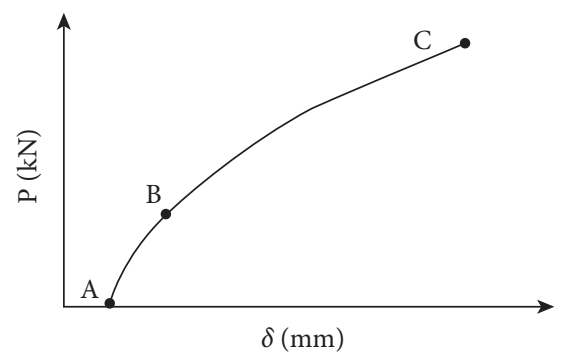

Figure 4: The typical load-deformation curve of damage strengthened beam.

time, the concrete web under the neutral axis was in tension, and the upper side of the neutral axis was in compression. The tensile steel reinforcements had not yielded, and the stress of the CFRP strips was 0, so it had not participated in the stress. The strengthened beam reached the key point $B$ as the load increased, at which time the steel reinforcement yielded in tension and the CFRP strips began to be stressed, as shown in Figure 5(b). With the increase of load, the yield area of the tensile steel reinforcements increased. After the steel reinforcements yielded, the CFRP strips bore the main tensile stress. The stress increased rapidly, and the stiffness decreased, and the deformation growth rate was greater than the load growth rate. The steel reinforcements in the pure bending section and the bending shear section had yielded. Although the CFRP strip had not reached the ultimate strength, it tended to the ultimate strength, which indicated that the strengthening effect of the CFRP strips had been reflected to a certain extent, as shown in Figure 5(c).

The stress distribution curve of the concrete beam, tensile steel reinforcements, and CFRP strips in the compression zone along the beam length at the characteristic point is shown in Figure 6.

The stress of the concrete section at points $\mathrm{A}$ and $\mathrm{B}$ was the largest in the pure bending section. The stress of the concrete section at point B was slightly higher than that of the concrete section at point $\mathrm{A}$, and the compressive stress of the concrete section at point $\mathrm{C}$ reached the maximum near the two loading points. The experimental failure modes were observed for the tested beam specimens: crushing failure of concrete in the compressive zone, wedge-shaped failure of the partial protective layer of concrete in the tensile zone, or a combination of both modes. In the simulation analysis, the concrete reached the ultimate compressive stress first, and the maximum position was near the loading point, which was consistent with the experimental failure mode. The section stress of tensile steel reinforcements at points $\mathrm{A}$ and $\mathrm{B}$ was the largest in the pure bending section. When the ultimate load was reached, the yield area of the tensile steel reinforcements increased, and the steel reinforcements of the pure bending section and most of the bending shear section reached the yield strength. The section stress of CFRP strips was zero at point A. At point B, the CFRP strips just took part in the stress, and the stress value was very small. When it reached point $\mathrm{C}$, the steel reinforcements had yielded, while the stress of CFRP strips reached $1562 \mathrm{~N} / \mathrm{mm}^{2}$, and the strength was basically fully utilized.

Through comparative analysis, the load-deformation curve and the stress distribution obtained by finite element analysis are in good agreement with the test results. The 
Concrete beam

S, S33

(avg : 75\%)

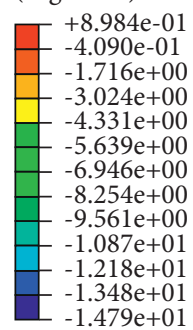

$-1.479 \mathrm{e}+01$

S, Mises (avg : 75\%)

$+3.895 \mathrm{e}+02$

$+3.570 \mathrm{e}+02$

$+3.246 \mathrm{e}+02$

$+2.921 \mathrm{e}+02$

$+2.596 \mathrm{e}+02$

$+2.272 \mathrm{e}+02$

$+1.947 \mathrm{e}+02$

$+1.623 \mathrm{e}+02$

$+1.298 \mathrm{e}+02$

$+9.738 \mathrm{e}+01$

$+6.492 \mathrm{e}+0$

$+3.247 \mathrm{e}+01$

$+1.411 \mathrm{e}-02$

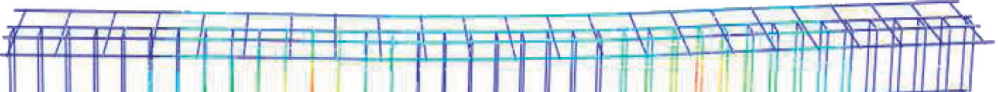

Steel reinforcements

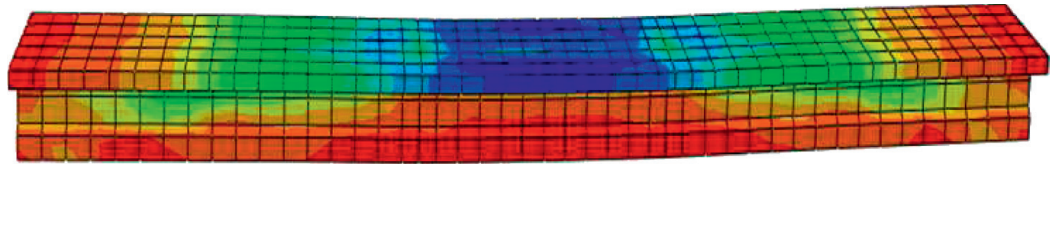

S, S33

(avg : 75\%)

$+0.000 \mathrm{e}+00$

$+0.000 \mathrm{e}+00$

$+0.000 \mathrm{e}+00$

$+0.000 \mathrm{e}+00$

$+0.000 \mathrm{e}+00$

$+0.000 \mathrm{e}+00$

$+0.000 \mathrm{e}+00$

$+0.000 \mathrm{e}+00$

$+0.000 \mathrm{e}+00$

$+0.000 \mathrm{e}+00$

$+0.000 \mathrm{e}+00$

$+0.000 \mathrm{e}+00$

(a)

Figure 5: Continued. 
Concrete beam

S, S33

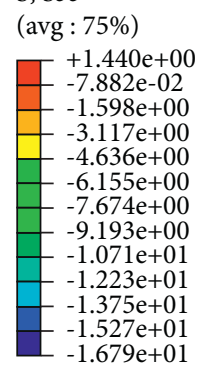

$-1.679 \mathrm{e}+01$

S, Mises (avg : 75\%)

$+3.882 \mathrm{e}+02$ $+3.558 \mathrm{e}+02$ $+3.235 \mathrm{e}+02$ $+2.912 \mathrm{e}+02$

$+2.588 \mathrm{e}+02$

$+2.588 \mathrm{e}+02$

$+1.942 \mathrm{e}+02$

$+1.618 \mathrm{e}+02$

$+1.295 \mathrm{e}+02$

$+9.717 \mathrm{e}+01$

$+6.483 \mathrm{e}+01$

$+3.250 \mathrm{e}+01$

$+1.658 \mathrm{e}-01$

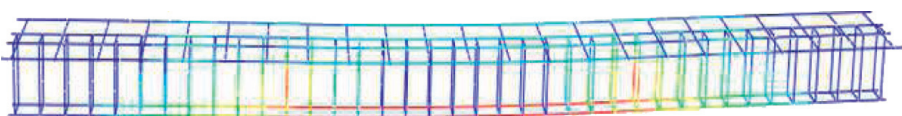

CFRP strips

S, S33

(avg : 75\%)

$+1.537 \mathrm{e}+02$

$+1.414 \mathrm{e}+02$

$+1.291 \mathrm{e}+02$

$+1.168 \mathrm{e}+02$

$+1.045 \mathrm{e}+02$

$+9.225 \mathrm{e}+01$

$+7.995 \mathrm{e}+01$

$+6.765 \mathrm{e}+0$

$+5.535 \mathrm{e}+01$

$+4.306 \mathrm{e}+01$

$+3.076 \mathrm{e}+01$

$+1.846 \mathrm{e}+01$

$+6.160 \mathrm{e}+00$

(b)

Figure 5: Continued. 
Concrete beam

S, S33

(avg : 75\%)

$+1.355 \mathrm{e}+00$

$-1.126 \mathrm{e}+00$

$-3.607 \mathrm{e}+00$

$-6.088 \mathrm{e}+00$

$-1.105 \mathrm{e}+0$

$-1.353 \mathrm{e}+01$

$-1.353 e+01$

$-1.601 \mathrm{e}+01$

$-1.849 \mathrm{e}+01$

$-2.097 \mathrm{e}+01$

$-2.345 \mathrm{e}+01$

$-2.593 \mathrm{e}+01$

$-2.841 \mathrm{e}+01$

Steel reinforcements

S, Mises

(avg : 75\%)

$+4.060 \mathrm{e}+02$

$+3.722 \mathrm{e}+02$

$+3.384 \mathrm{e}+02$

$+3.046 \mathrm{e}+02$

$+2.707 \mathrm{e}+02$

$+2.369 \mathrm{e}+02$

$+2.031 \mathrm{e}+02$

$+1.693 \mathrm{e}+02$

$+1.355 \mathrm{e}+02$

$+1.017 \mathrm{e}+02$

$+6.785 \mathrm{e}+01$

$+3.404 \mathrm{e}+01$

$+2.240 \mathrm{e}-01$

CFRP strips

S, S33
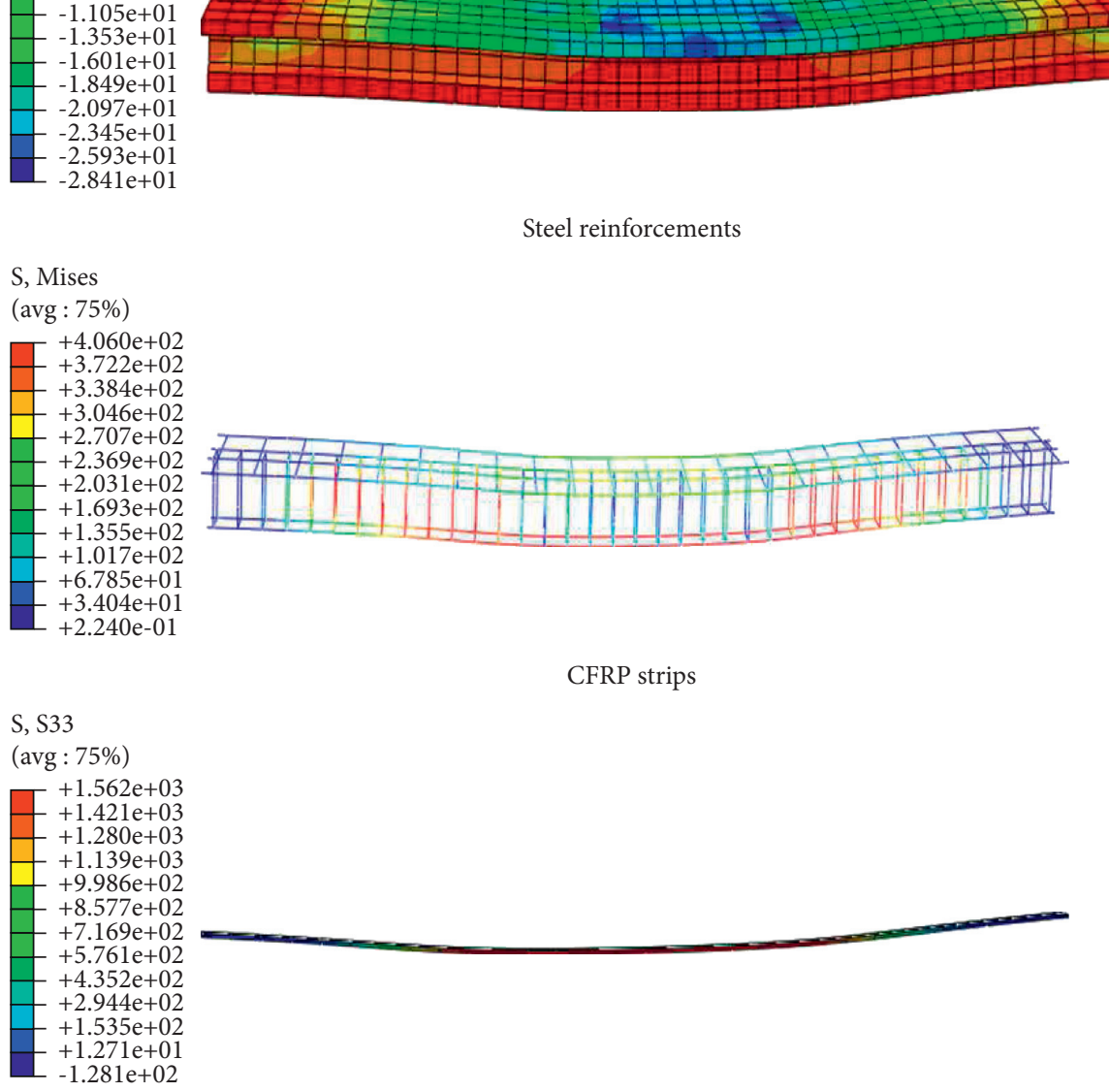

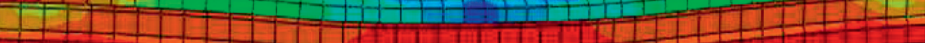

$1{ }^{2}$ 


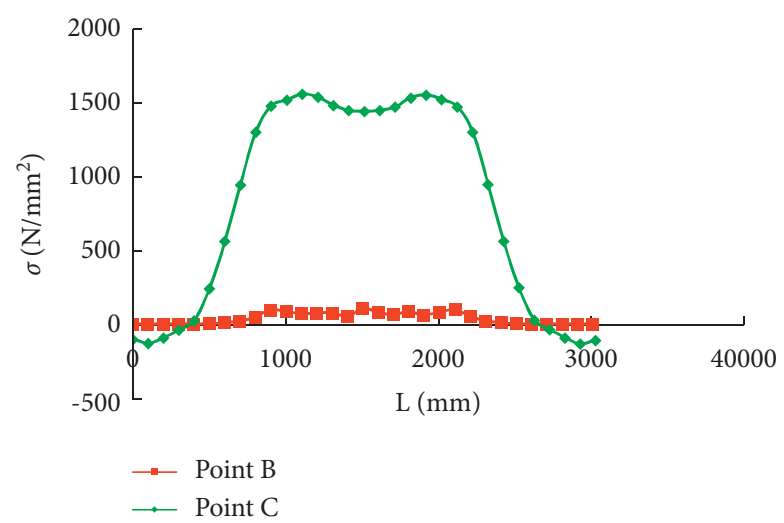

(c)

FIGURE 6: Section stress distribution along the beam length: (a) section of concrete, (b) section of steel reinforcements, and (c) section of CFRP strips.

finite element model established in this paper could accurately simulate the flexural behaviors of PRC beams strengthened with NSM CFRP strips.

\section{Parametric Analysis}

In order to better analyze the flexural behaviors of the strengthened beam, this simulation considered the concrete strength grade and the amount of CFRP strips in the case of directly strengthened beams without damage. In the case of damage strengthened beam, the times of cycle number took $1,50,100,200$, and 500 as parameters, and the upper limit of overload amplitude took $70 \mathrm{kN}, 90 \mathrm{kN}, 120 \mathrm{kN}, 130 \mathrm{kN}$, $140 \mathrm{kN}$, and $150 \mathrm{kN}$ as parameters.

\subsection{Directly Strengthened Beams}

4.1.1. Concrete Strength Grade. Taking five strength grades of C30, C40, C50, C60, and C70 as parameters, the loaddeformation curve of the directly strengthened beam under each concrete strength grade is shown in Figure 7.

It shows that in the elastic stage before concrete cracking, under different strength grades, the slope of the load-deformation curve was basically the same, and the cracking load was basically the same. In the second stage of the load-deformation curve, with the increase of concrete strength grade, the yield load of the strengthened beam slightly increased, but the increase is not obvious. In the third stage of the load-deformation curve, the concrete strength grade had a great influence on the ultimate load of the strengthened beam. The higher the concrete strength grade, the greater the ultimate load.

The ultimate loads of strengthened beams were $230 \mathrm{kN}$, $268.6 \mathrm{kN}, 275.9 \mathrm{kN}, 278.1 \mathrm{kN}$, and $278.9 \mathrm{kN}$, respectively. Compared with the strengthened beam of $\mathrm{C} 30$, the other strengthened beams were increased by $16.8 \%, 20.0 \%, 20.9 \%$, and $21.3 \%$, respectively. It can be seen that with the improvement of concrete strength, the ultimate load was improved. When the concrete strength grade exceeded C50, the improvement of the ultimate load was limited with the increase of concrete strength grade.

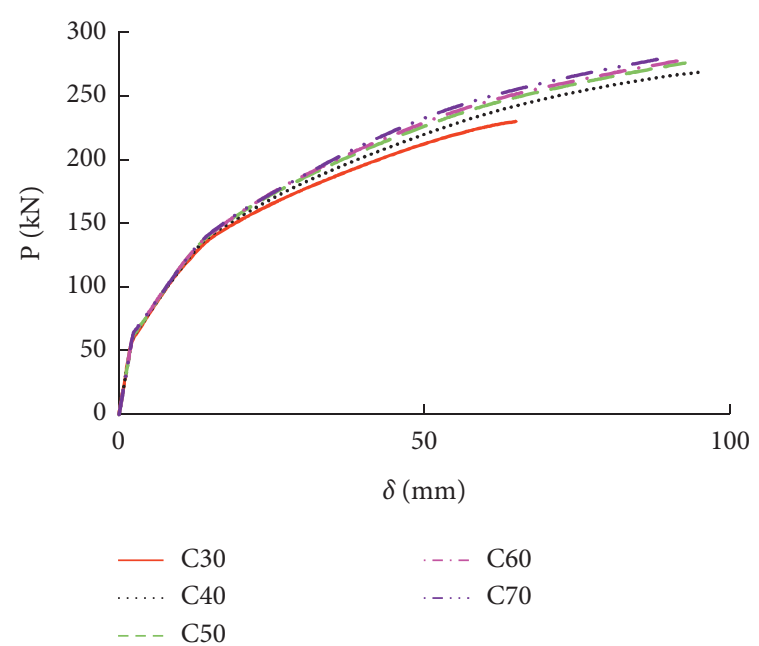

Figure 7: The load-deformation curve of different strength grades of concrete.

The distribution curve of stress along the beam length under different concrete strength grades is shown in Figure 8 . As seen in the figure, the maximum compressive stress of the concrete section occurred at the inner side near the two loading points. Due to the influence of the steel plate at the loading point, the concrete stress decreased slightly. The further away from the loading point, the concrete compressive stress along the beam length showed a nonlinear symmetric decreasing trend. The maximum tensile stress occurred in the pure bending section and part of the shear span section and then decreased gradually to both ends of the beam. The tensile stress of the CFRP strip section was the largest near the loading point in the pure bending section and decreased nonlinearly to both ends of the beam.

When the concrete strength grade was $\mathrm{C} 30$, the maximum compressive stress of concrete was located on the inner side of the loading point. At this time, the stress of CFRP strips had not reached the ultimate strength. When the concrete strength grade was $\mathrm{C} 40$, the compressive stress of concrete in the compression zone reached the ultimate compressive 


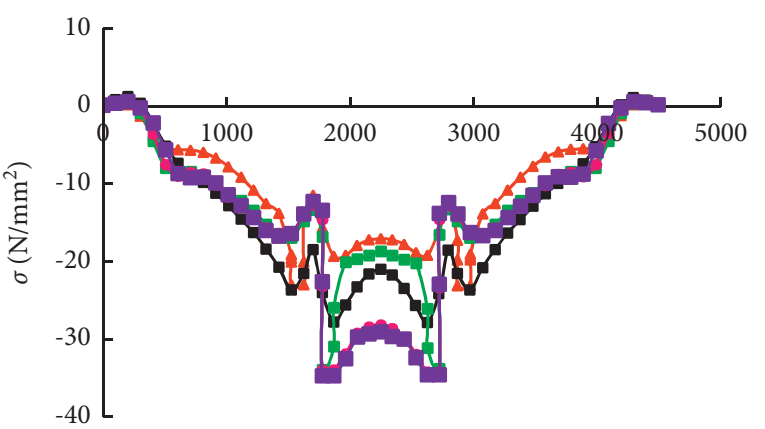

$\mathrm{L}(\mathrm{mm})$

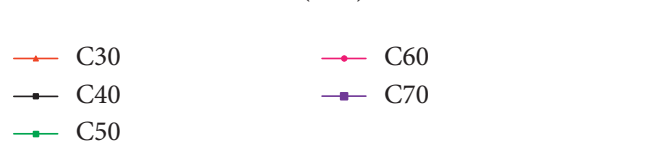

(a)
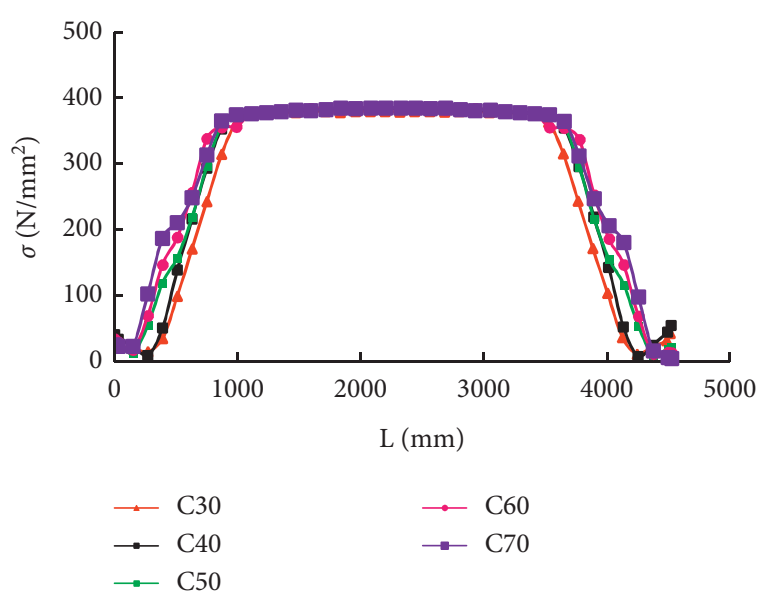

(b)

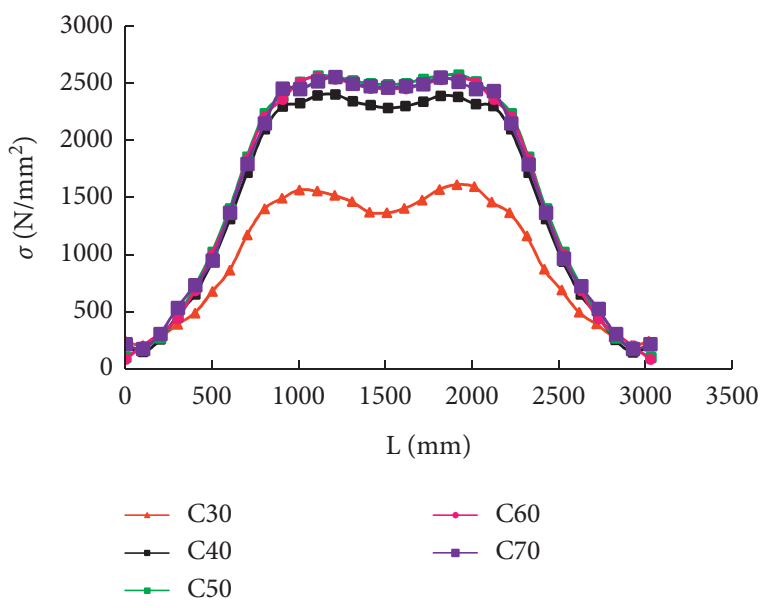

(c)

Figure 8: Section stress distribution along the beam length under different strength grades of concrete: (a) section of concrete, (b) section of steel reinforcements, and (c) section of CFRP strips.

stress, and the tensile stress of CFRP strips tended to the ultimate strength. When the concrete strength grade was C50, the maximum compressive stress of concrete increased obviously, and the tensile stress of CFRP strips reached the ultimate strength. With the increase of concrete strength grade, the compressive stress of concrete basically no longer increased. The results showed that with the increase of concrete strength grade, the compressive stress of concrete and the tensile stress of CFRP strips gradually increased obviously. When the concrete strength grade exceeded C50, the compressive stress of concrete and the tensile stress of CFRP strips no longer increased obviously, and the maximum tensile stress of steel reinforcements did not change much with the increase of concrete strength grade. However, the maximum tensile stress range gradually extended to both ends of the beam with the increase of concrete strength grade.

4.1.2. Amount of CFRP Strips. The load-deformation curves of different CFRP strips amount were calculated by

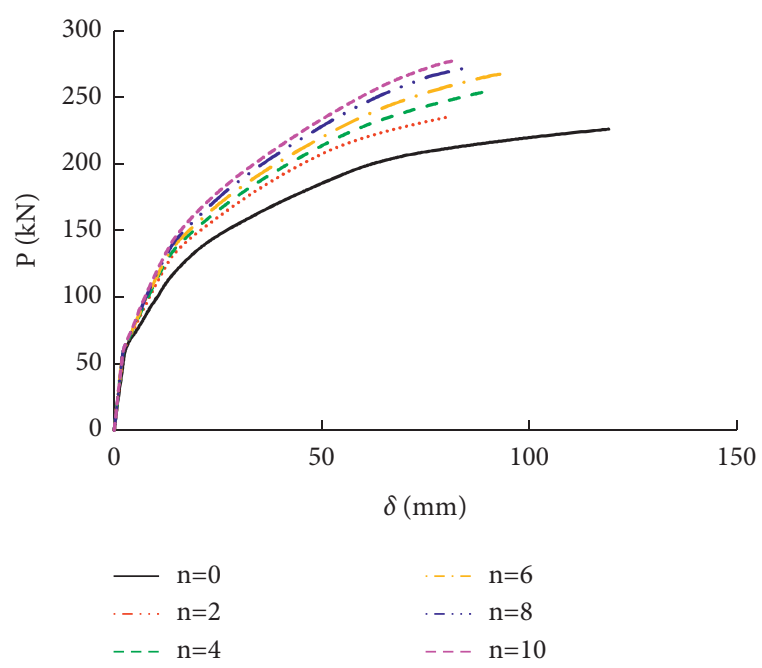

FIGURE 9: The load-deformation curves of different amounts of CFRP strips. 


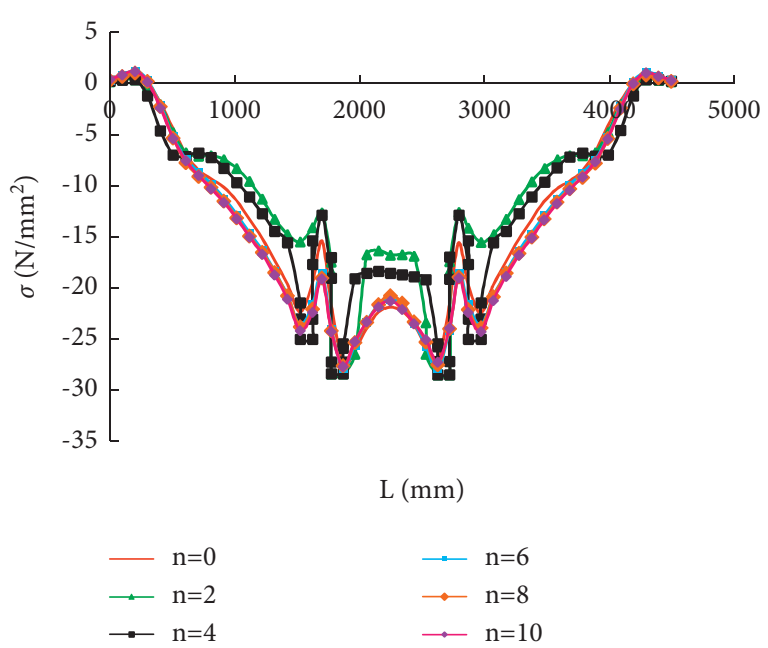

(a)

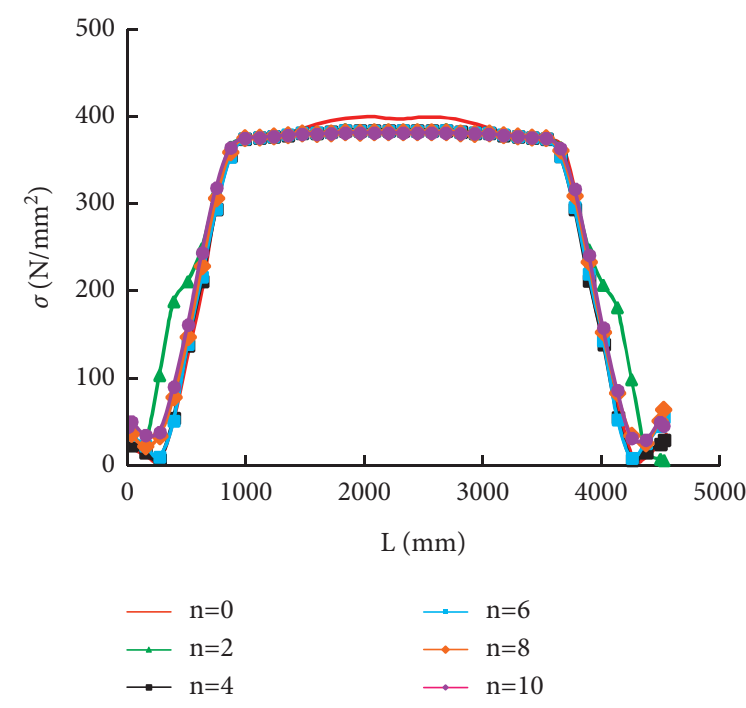

(b)

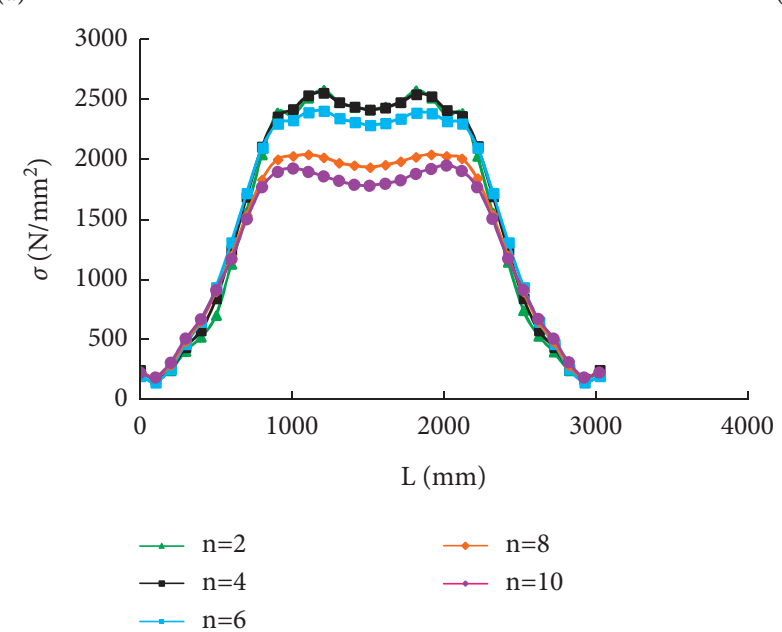

(c)

FIGURE 10: Section stress distribution along the beam length under different amounts of CFRP strips: (a) section of concrete, (b) section of steel reinforcements, and (c) section of CFRP strips.

ABAQUS, as shown in Figure 9. The stress distribution curve along the beam length is shown in Figure 10.

Figure 9 shows that the amount of CFRP strips had a certain impact on the ultimate loads of the beams. When the amount of CFRP strips was 2, 4, 6, 8, and 10, the ultimate loads were $235.4 \mathrm{kN}, 254.3 \mathrm{kN}, 268.6 \mathrm{kN}, 271.7 \mathrm{kN}$, and $278.1 \mathrm{kN}$, respectively. The larger the amount, the higher the ultimate load. Compared with the unstrengthened beam, the ultimate loads were increased by $4.1 \%, 12.5 \%, 18.8 \%, 20.2 \%$, and $23.0 \%$, respectively. The ultimate loads of beams strengthened with 6,8 , and 10 CFRP strips were increased by $5.6 \%, 6.8 \%$, and $9.4 \%$, respectively, compared with that of beams strengthened with 4 CFRP strips. The results show that the amount of CFRP strips had an obvious effect on improving the ultimate load of the strengthened beam.

Figure 10 shows that when the load reached the ultimate load, the steel reinforcements of the unstrengthened beam yielded and the concrete reached the ultimate compressive stress. When the amount of CFRP strips was 2 or 4 , the tensile stress of CFRP strips reached the ultimate strength, and the distribution curve of tensile stress along the beam length was basically the same. When the amount of CFRP strips was 6 , the concrete in the compression zone reached the ultimate compressive stress at the loading point, and the CFRP strips reached the ultimate strength. When the amount of CFRP strips was more than 6, the concrete reached the ultimate compressive stress, but the CFRP strips did not reach the ultimate strength. The results show that with the increase of CFRP strips, the compressive stress of concrete slightly increased, and the tensile stress of CFRP strips gradually decreased. When the amount of CFRP strips increased to 6,8 , and 10 , the increase of concrete compressive stress was limited, and the distribution curves along the beam length basically coincided. However, the maximum tensile stress of steel reinforcements had no change with the increase of CFRP strips. When the amount of CFRP 

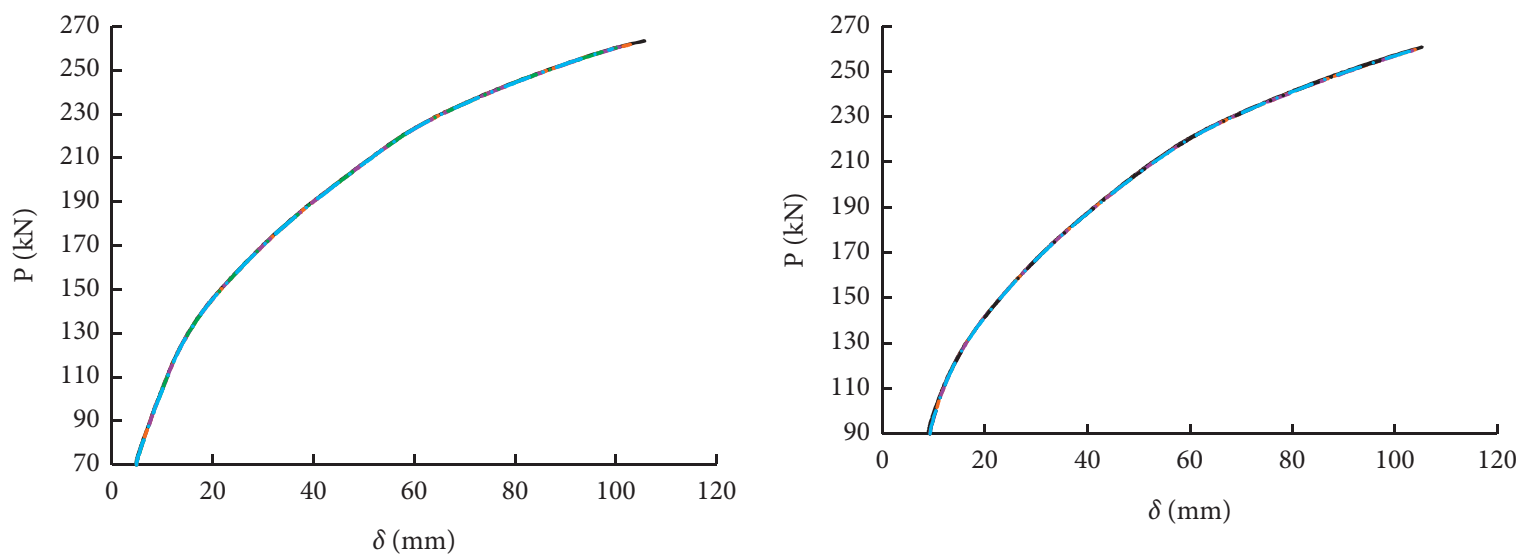

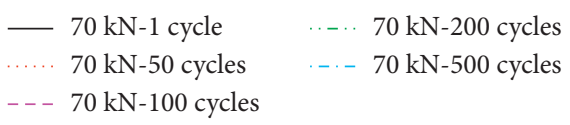

(a)
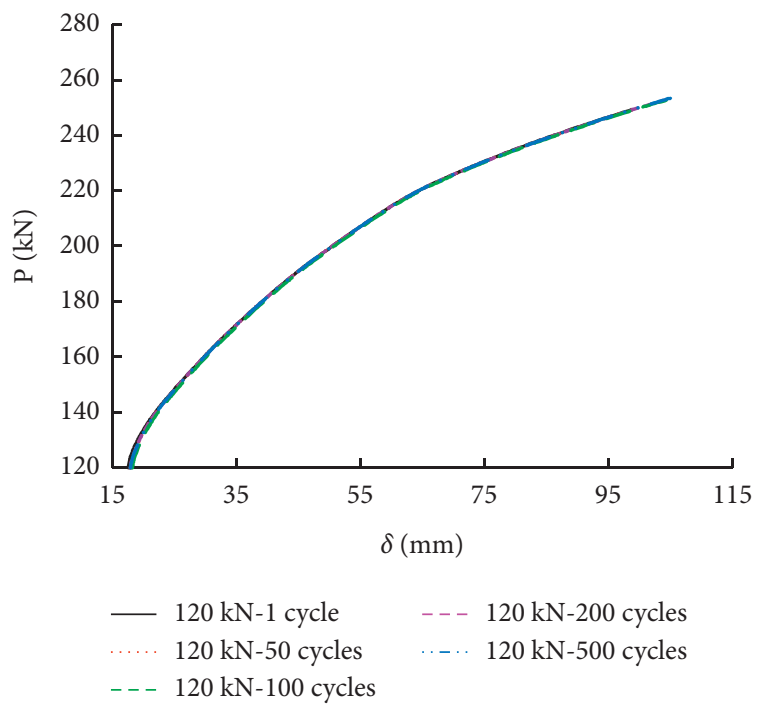

(c)

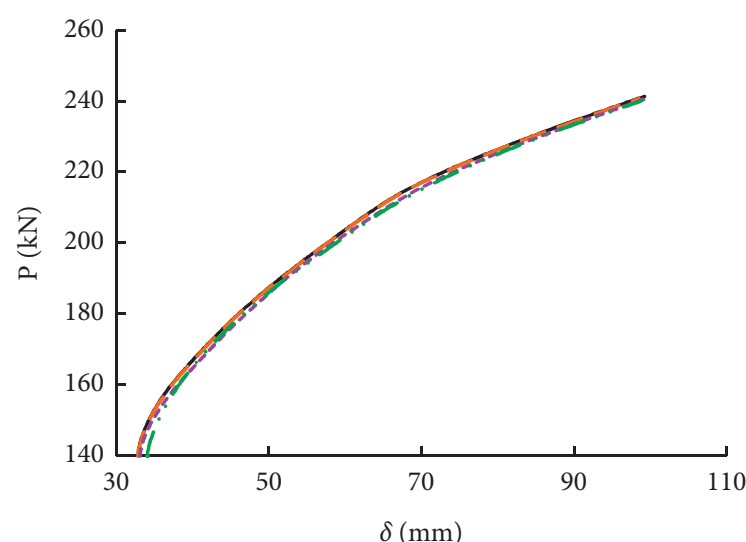

$\begin{array}{llll}-140 \mathrm{kN}-1 \text { cycle } & \ldots . . & 140 \mathrm{kN}-100 \text { cycles } \\ --- & 140 \mathrm{kN}-50 \text { cycles } & \cdots & 140 \mathrm{kN}-200 \text { cycles }\end{array}$

(e)

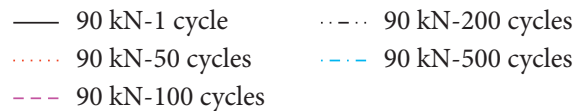

(b)

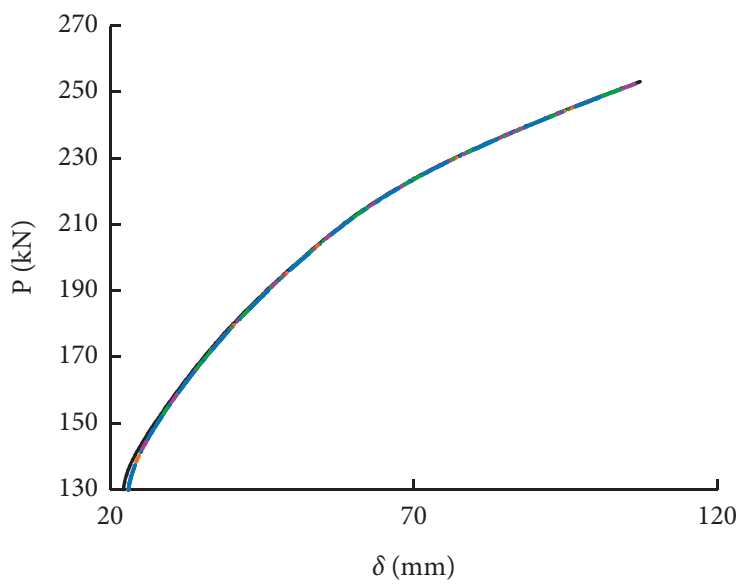

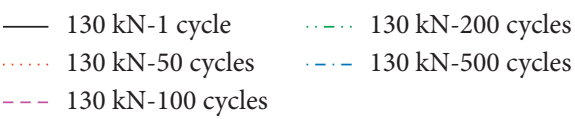

(d)

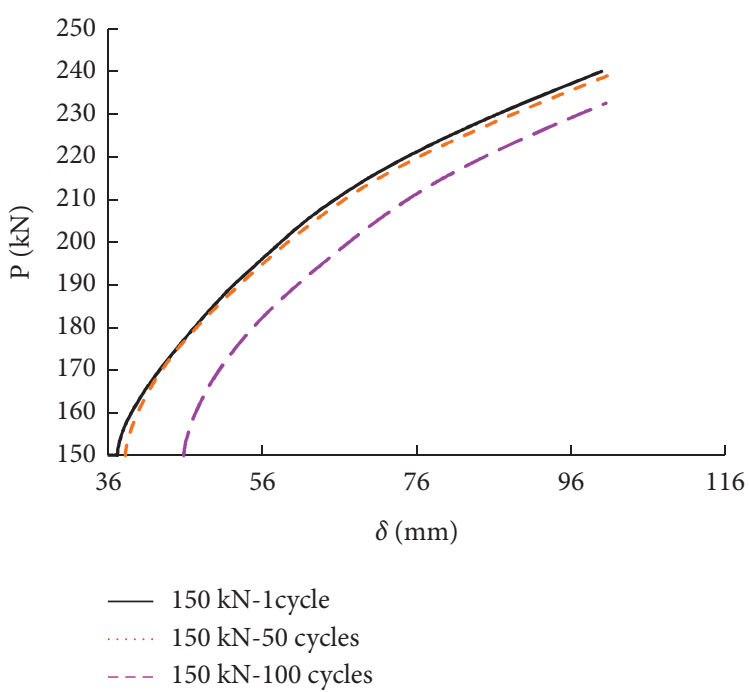

(f)

Figure 11: Load-deformation curves of different cycle numbers: (a) overload amplitude $70 \mathrm{kN}$, (b) overload amplitude $90 \mathrm{kN}$, (c) overload amplitude $120 \mathrm{kN}$, (d) overload amplitude $130 \mathrm{kN}$, (e) overload amplitude $140 \mathrm{kN}$, and (f) overload amplitude $150 \mathrm{kN}$. 

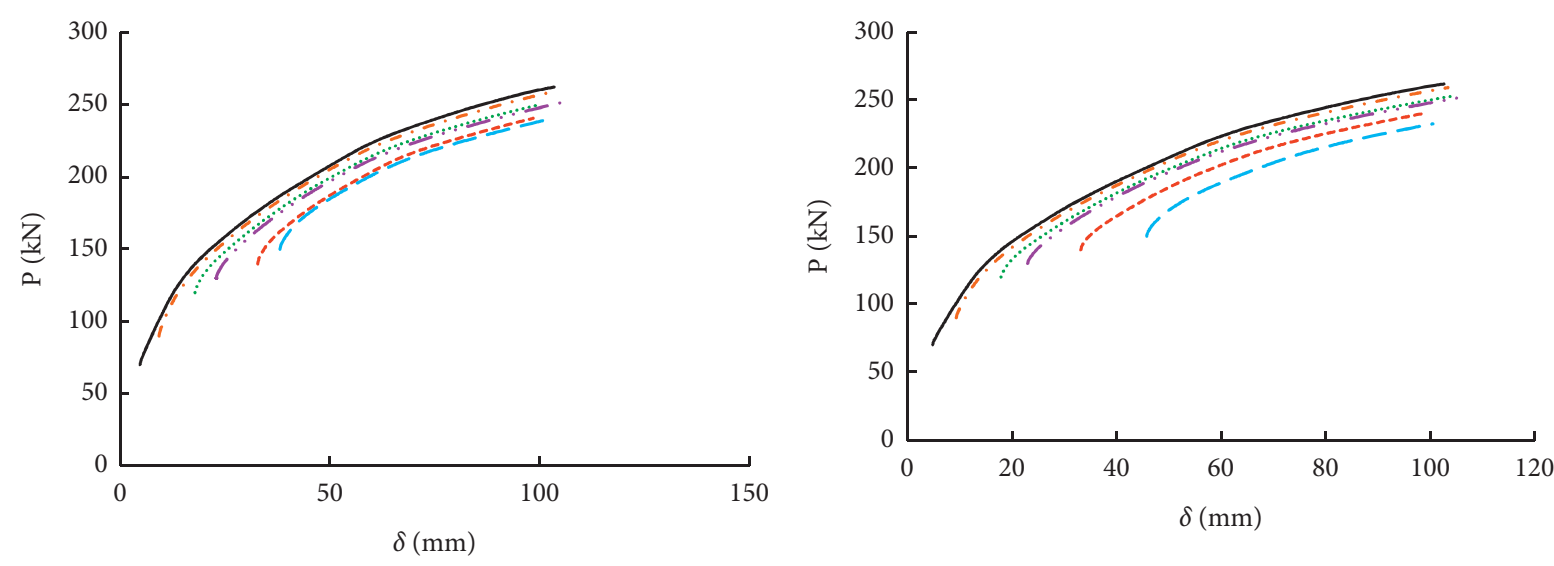

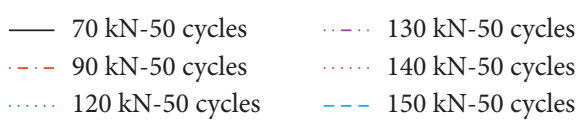

(a)

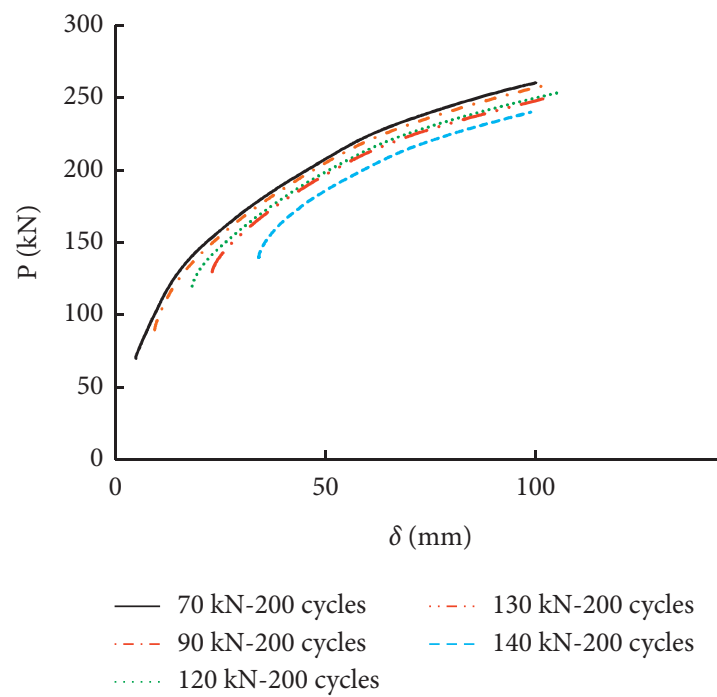

(c)

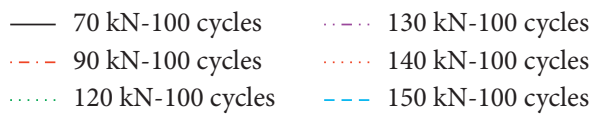

(b)

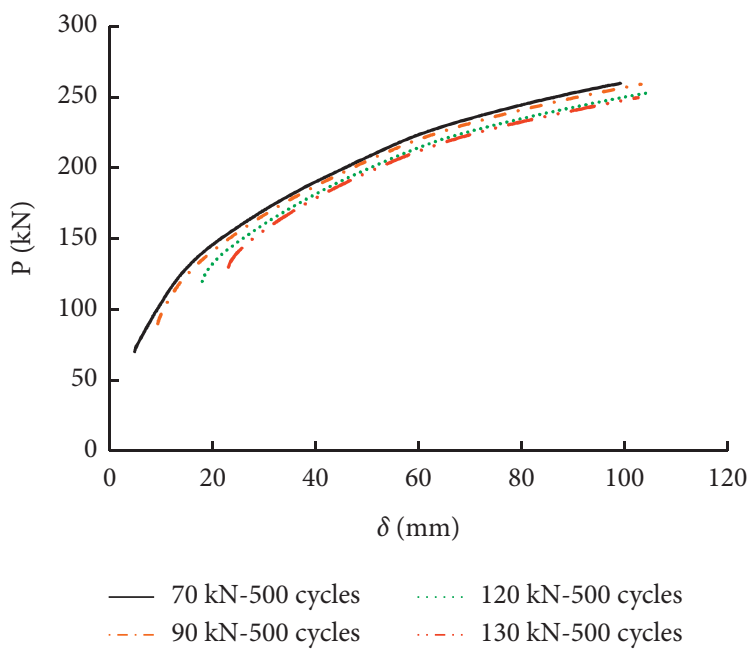

(d)

FIGURE 12: Load-deformation curves of different overload amplitude: (a) cycle numbers 50, (b) cycle numbers 100, (c) cycle numbers 200, and (d) cycle numbers 500 .

strips was more than 6, the strength of CFRP strips was not fully utilized.

\subsection{Damage Strengthened Beams}

4.2.1. Cycle Number. After cycle loading once, 50, 100, 200, and 500 times, then the beams were strengthened with CFRP strips under loading. The load-deformation curves of the beams with the same overload amplitude were obtained as shown in Figure 11.

It can be seen that when the overload amplitude was less than $130 \mathrm{kN}(51.5 \%$ of the ultimate load) and the cycle number was less than 500 times, the cycle number had little effect on the ultimate load and deformation under the same overload amplitude. When the upper limit of amplitude was $140 \mathrm{kN}$ ( $62 \%$ of the ultimate load), the ultimate load and deformation were basically not affected by 1 and 50 cycles. When the cycle number was 200 times, the deformation increased obviously. It was because that the damage was the dominant factor and the deformation increased slightly due to the increase of cycle number. When the cycle number reached 243 times, the specimen failed before reinforcement. When the upper limit of overload amplitude was $150 \mathrm{kN}$ ( $66.3 \%$ of the ultimate load), the deformation of 50 cycles was slightly greater than that of one cycle, and the ultimate load decreased slightly. When the cycle number was 100 times, the deformation increased significantly, and the ultimate load decreased significantly under the same level load. When the cycle number reached 112 times, the specimen failed before reinforcement. 
The results show that when the overload amplitude was less than $60 \%$ of the ultimate load, the cycle number (within 500 times) had no obvious effect on the yield load, ultimate load, and deformation. When the overload amplitude was higher than $60 \%$ of the ultimate load, the cycle number had an effect on the ultimate load and deformation. With the increase of the cycle number, the deformation increased and the ultimate load decreased.

4.2.2. Overload Amplitude. The load-deformation curves with different upper limits of overload amplitude under the same cycle numbers (50, 100, 200, and 500 times) were obtained, as shown in Figure 12.

It can be seen that with the increase of overload amplitude, the ultimate load decreased, and the deformation increased under the same cycle number. When the overload amplitude was small, the change of ultimate load and deformation was small. When the overload amplitude was large, the deformation increased obviously, and the ultimate load decreased obviously.

\section{Calculation of Load Carrying Capacity}

According to the experimental study of the PRC beams strengthened with NSM CFRP strips and the force balance, the flexural carrying capacity of the PRC beams strengthened with CFRP strips is obtained as follows:

$$
\begin{aligned}
M_{u}= & 0.4 f_{c} b x_{c u}^{2}+0.8 f_{c}\left(b_{c}-b\right) h_{c}\left(x_{c u}-0.5 h_{c}\right) \\
& +f_{y}^{\prime} A_{s}^{\prime}\left(x_{c u}-a_{s}^{\prime}\right)+f_{y} A_{s}\left(h-x_{c u}-a_{s}\right) \\
& +f_{p y} A_{p}\left(h-x_{c u}-a_{p}\right)+E_{f} A_{f}\left[\varepsilon_{f u}\right]\left(h-x_{c u}-a_{f}\right)
\end{aligned}
$$

where $f_{c}$ is the axial compressive strength of concrete and $b_{c}$ and $b$ are the width of concrete flange plate and web plate, respectively. $h$ is the height of the concrete beam. $x_{c u}$ is the height of concrete compression zone. $f_{y}$ and $f_{y}^{\prime}$ are the design value of tensile and compressive strength of tensile and compressive steel reinforcements, respectively. $f_{p y}$ is the design value of tensile strength of prestressed steel reinforcements. $A_{s}, A_{s}^{\prime}, A_{p}$, and $A_{f}$ are the cross-sectional areas of tensile steel reinforcements, compressive steel reinforcements, prestressed steel reinforcements, and CFRP strips, respectively. $a_{s}, a_{s}^{\prime}, a_{p}$, and $a_{f}$ are the distance from the resultant force point of tensile steel reinforcements, compressive steel reinforcements, prestressed steel reinforcements, and CFRP strips to the near side of the section, respectively. $E_{f}$ is the elastic modulus of CFRP strips. $\left[\varepsilon_{f u}\right]$ is the allowable tensile strain of CFRP strips, $\left[\varepsilon_{f u}\right]=\min \left(2 \varepsilon_{f u} / 3,0.01\right)$.

The ultimate load of each specimen calculated by the finite element method is summarized, and the ultimate load calculated by the theoretical formula is compared with the test results, as shown in Table 2.

It can be seen that the simulated value and theoretical value of the ultimate load of each specimen are in good agreement with the experimental value, which indicates that the model established is reasonable, and the calculation
TABLE 2: Comparison of simulated value, theoretical value, and experimental value.

\begin{tabular}{lccccc}
\hline Specimens & $P_{u}^{s}(\mathrm{kN})$ & $P_{u}^{e}(\mathrm{kN})$ & $P_{u}^{c}(\mathrm{kN})$ & $P_{u}^{s} / P_{u}^{e}$ & $P_{u}^{c} / P_{u}^{e}$ \\
\hline PCB0 & 226.1 & 229.4 & 211.7 & 0.985 & 0.923 \\
MPCB1 & 256.8 & 245.8 & 249.9 & 1.045 & 1.017 \\
MPCB2 & 255.3 & 260.7 & 249.9 & 0.979 & 0.959 \\
MPCB3 & 255.9 & 257.6 & 249.9 & 0.993 & 0.970 \\
MPCB4 & 240.6 & 254.6 & 249.9 & 0.945 & 0.982 \\
\hline
\end{tabular}

Note: $P_{u}^{s}$ is the simulated value, $P_{u}^{e}$ is the experimental value, and $P_{u}^{c}$ is the theoretical value.

result of load carrying capacity calculation formula has high accuracy, which can be applied to actual engineering calculation.

\section{Conclusions}

Based on numerical analysis, experimental verification, and theoretical analysis, this paper studied the flexural behavior of PRC beams strengthened with NSM CFRP strips. The following conclusions were obtained:

(1) The model established was verified by experiments, and the calculated results were in good agreement with the experimental results, which showed that it was feasible to use the model to analyze the flexural behavior of PRC beams strengthened with NSM CFRP strips.

(2) For directly strengthened beams, the concrete strength grade (C30 C70) had a certain influence on the carrying capacity of PRC strengthened with CFRP strips. With the increase of concrete strength, the cracking load was basically unchanged, the yield load was slightly increased, and the ultimate load was significantly improved. Compared with the strengthened beams of strength grade with C30, the other strengthened beams were increased by $16.8 \%$, $20.0 \%, 20.9 \%$, and $21.3 \%$, respectively. When the concrete strength grade exceeded C50, the improvement of the ultimate load was limited with the increase of concrete strength grade. The larger the amount of CFRP strips $(n=2,4,6,8$, and 10$)$, the higher the ultimate load. Compared with the unstrengthened beams, the ultimate load was increased by $4.1 \%, 12.5 \%, 18.8 \%, 20.2 \%$, and $23.0 \%$, respectively. When the amount of CFRP strips exceeded 6, the strength of CFRP strips could not be fully utilized.

(3) When the overload amplitude was less than $60 \%$ of the ultimate load, the cycle number (within 500 times) had little effect on the yield load, ultimate load, and deformation. When the overload amplitude was higher than $60 \%$ of the ultimate load, the cycle number had an effect on the ultimate load and deformation. With the increase of the cycle number, the deformation increased, and the ultimate load decreased. With the increase of overload amplitude, the ultimate load decreased, and the deformation 
increased under the same cycle number. When the overload amplitude was small, the change of ultimate load and deformation was small. When the overload amplitude was large, the deformation increased obviously, and the ultimate load decreased obviously.

(4) The formula of the flexural carrying capacity of PRC beams strengthened with NSM CFRP strips was established. The calculated results were in good agreement with the experimental results. The formula was reasonable and could be applied to practical engineering calculations.

\section{Data Availability}

Some or all data used during the study are available from the corresponding author upon request.

\section{Conflicts of Interest}

The authors declare that they have no conflicts of interest.

\section{Acknowledgments}

The authors would like to acknowledge the research grant received from the National Science Foundation of China (Grant no. 52078306) and the Natural Science Foundation of Liaoning Province (Grant nos. 2021-BS-278, 2019-ZD-0552, 2019-MS-158, and 2020-BS-262).

\section{References}

[1] S. S. Zhang and T. Yu, "Analytical solution for interaction forces in beams strengthened with near-surface mounted round bars," Construction and Building Materials, vol. 106, pp. 189-197, 2016.

[2] American Concrete Institute (Aci), Guide for the Design and Construction of Externally Bonded FRP Systems for Strengthening concrete Structures, ACI-440 2R, Farmington Hills, Michigan, 2008.

[3] L. De Lorenzis and J. G. Teng, "Near-surface mounted FRP reinforcement: an emerging technique for strengthening structures," Composites Part B: Engineering, vol. 38, no. 2, pp. 119-143, 2007.

[4] R. El-Hacha and S. H. Rizkalla, "Near-surface-mounted fiberreinforced polymer reinforcements for flexural strengthening of concrete structures," Structural Journal, vol. 101, no. 5, pp. 717-726, 2004.

[5] M. Akter Hosen, M. Zamin Jumaat, and A. B. M. Saiful Islam, "Inclusion of CFRP-epoxy composite for end anchorage in NSM-epoxy strengthened beams," Advances in Materials Science and Engineering, vol. 2015, Article ID 812797, 10 pages, 2015.

[6] W. C. Xue, L. Zeng, and Y. Tan, "Studies on design theories of concrete beams strengthened with prestressed CFRP plates," Journal of Building Structures, vol. 29, no. 4, pp. 127-133, 2008.

[7] X. J. He and L. Xu, "Experimental study on the flexural behavior of reinforced concrete beams strengthened with nearsurface mounted CFRP laminates," China Civil Engineering Journal, vol. 41, no. 12, pp. 14-20, 2008.
[8] M. Emara, L. Torres, M. Baena, C. Barris, and X. Cahís, "Bond response of NSM CFRP strips in concrete under sustained loading and different temperature and humidity conditions," Composite Structures, vol. 192, pp. 1-7, 2018.

[9] L. Anania, A. Badalà, and G. Failla, "Increasing the flexural performance of RC beams strengthened with CFRP materials," Construction and Building Materials, vol. 19, no. 1, pp. 55-61, 2005.

[10] M. Emara, C. Barris, M. Baena, L. Torres, and J. Barros, "Bond behavior of NSM CFRP laminates in concrete under sustained loading," Construction and Building Materials, vol. 177, pp. 237-246, 2018.

[11] M. I. Kabir, M. Subhani, R. Shrestha, and B. Samali, "Experimental and theoretical analysis of severely damaged concrete beams strengthened with CFRP," Construction and Building Materials, vol. 178, pp. 161-174, 2018.

[12] J. G. Teng, L. De Lorenzis, B. Wang, R. Li, T. N. Wong, and L. Lam, "Debonding failures of RC beams strengthened with near surface mounted CFRP strips," Journal of Composites for Construction, vol. 10, no. 2, pp. 92-105, 2006.

[13] S. E. El-Gamal, A. Al-Nuaimi, A. Al-Saidy, and A. Al-Lawati, "Efficiency of near surface mounted technique using fiber reinforced polymers for the flexural strengthening of RC beams," Construction and Building Materials, vol. 118, pp. 52-62, 2016.

[14] S. J. E. Dias, J. A. O. Barros, and W. Janwaen, "Behavior of RC beams flexurally strengthened with NSM CFRP laminates," Composite Structures, vol. 201, pp. 363-376, 2018.

[15] J. Yang and L. Wang, "Experimental research on flexural behaviors of damaged PRC beams strengthened with NSM CFRP strips," Construction and Building Materials, vol. 190, pp. 265-275, 2018.

[16] L. R. F. D. Aashto, Bridge Design Specifications, SI Units, AASHTO, Washington, DC, USA, 3rd edition, 2004.

[17] Y. Z. Zhang, "Finite element analysis on seismic performance of giant CFRT columns with load transfer details," Journal of Building Structures, vol. 39, no. 11, pp. 20-28, 2018.

[18] X. Y. Xiong and S. Zhang, "Seismic behavior study of hybrid reinforcement concrete beams with bonded and unbonded prestressed tendons under horizontal low cyclic loading," Building Structure, vol. 48, no. 8, pp. 41-45, 2018.

[19] Z. Zhuang, F. Zhang, and S. Cen, ABAQUS Nonlinear Finite Element Analysis and Examples, Science Press, Beijing, China, 2005.

[20] Y. Ye, Flexural Behavior of Stone Beams/slabs Reinforced with Prestressed NSM CFRP Bars, FuJian: Hua Qiao University, Quanzhou, China, 2014.

[21] D. H. Cheng, X. Ye, and L. B. Zhang, "Research of mechanical properties on loaded concrete beam reinforced with prestressed CFRP sheet," China Civil Engineering Journal, pp. 319-328, 2013.

[22] D. D. Ge, Z. F. Zhou, and Q. S. Miao, "Progressive-collapse simulation of reinforced concrete frame structure subjected to earthquake," China Civil Engineering Journal, pp. 50-55, 2014. 